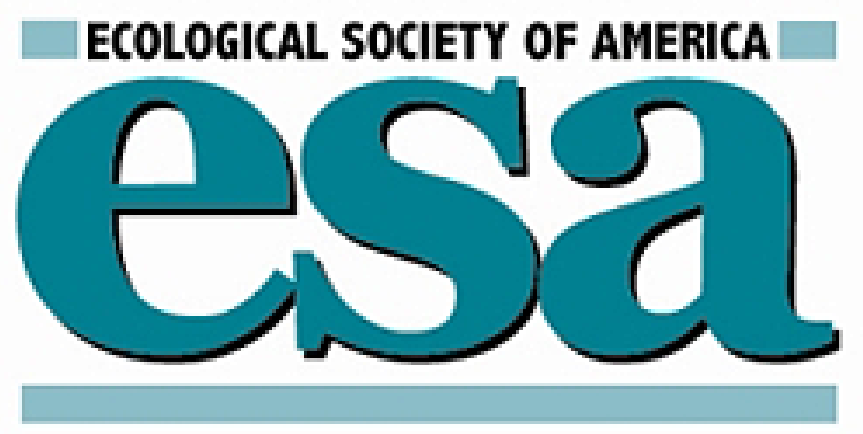

Costs and Benefits of Capsaicin-Mediated Control of Gut Retention in Dispersers of Wild Chilies

Author(s): Joshua J. Tewksbury, Douglas J. Levey, Meribeth Huizinga, David C. Haak and Anna Traveset

Source: Ecology, Vol. 89, No. 1 (Jan., 2008), pp. 107-117

Published by: Ecological Society of America

Stable URL: http://www.jstor.org/stable/27651513

Accessed: 19/02/2015 05:26

Your use of the JSTOR archive indicates your acceptance of the Terms \& Conditions of Use, available at http://www.jstor.org/page/info/about/policies/terms.jsp

JSTOR is a not-for-profit service that helps scholars, researchers, and students discover, use, and build upon a wide range of content in a trusted digital archive. We use information technology and tools to increase productivity and facilitate new forms of scholarship. For more information about JSTOR, please contact support@jstor.org. 


\title{
COSTS AND BENEFITS OF CAPSAICIN-MEDIATED CONTROL OF GUT RETENTION IN DISPERSERS OF WILD CHILIES
}

\author{
Joshua J. Tewksbury, ${ }^{1,5}$ Douglas J. Levey, ${ }^{2}$ Meribeth Huizinga, ${ }^{3}$ David C. Haak, ${ }^{1}$ and Anna Traveset ${ }^{4}$ \\ ${ }^{1}$ Department of Biology, 106 Kincaid Hall, Box 351800, University of Washington, Seattle, Washington 98195 USA \\ ${ }^{2}$ Department of Zoology, University of Florida, Gainesville, Florida 32611 USA \\ ${ }^{3}$ Department of Biology, Colorado State University, Fort Collins, Colorado 80523 USA \\ ${ }^{4}$ Mediterranean Institute of Advanced Studies, IMEDEA (CSIC-UIB), Miquel Marqués, 21 E07190 Esporles, Mallorca, \\ Balearic Islands, Spain
}

\begin{abstract}
A fundamental way in which animal-dispersed plants can influence the viability and distribution of dispersed seeds is through control of retention time in the guts of dispersers. Using two species of wild chilies and their dispersers, we examined how chemical and physical properties of fruits and seeds mediate this interaction. Capsicum chacoense is polymorphic for pungency, occurs in Bolivia, and is dispersed mostly by elaenias. Capsicum annuum is not polymorphic, occurs in Arizona (USA), and is dispersed mostly by thrashers.

We first tested whether capsaicin, the substance responsible for the pungency of chilies, affects gut retention time of seeds in primary dispersers. Capsaicin slowed gut passage of seeds but did so in a manner that differed greatly between bird species because the constipative effects of capsaicin occurred only after an 80-minute time lag. Elaenias in Bolivia held only $6 \%$ of $C$. chacoense seeds for $>80$ minutes, whereas thrashers in Arizona held $78 \%$ of $C$. annuum seeds for $>80$ minutes.

Next we examined the effects of retention time on seed viability and germination. Increased retention resulted in a greater proportion of seeds germinating in C. annuum, had no effects on non-pungent $C$. chacoense, and had negative effects on pungent $C$. chacoense. These divergent effects are explained by differences in seed coat morphology: seed coats of pungent $C$. chacoense are 10-12\% thinner than those of the other two types of seeds. Thus, longer retention times damaged seeds with the thinnest seed coats. In $C$. annuum, seed viability remained high regardless of retention time, but germination increased with retention, suggesting a role for scarification.

Thus, in $C$. annuum, fruit chemistry appears well matched with seed morphology and disperser physiology: capsaicin extends gut retention for most seeds, resulting in greater seed scarification and higher germination rates. Increased retention of pungent $C$. chacoense seeds is detrimental, but because the primary consumers have short retention times, capsaicin slows only a small proportion of seeds, minimizing negative effects. These results illustrate the importance of context in studies of fruit secondary metabolites. The same chemical can have different impacts on plant fitness depending on its morphological, physiological, and ecological context.
\end{abstract}

Key words: capsaicin capsaicinoids; Capsicum annuum; Capsicum chacoense; chilies; Elaenia parvirostris; frugivory; fruit-frugivore interactions; fruit secondary metabolites; gut retention; scarification; seed germination; Toxostoma curvirostre.

\section{INTRODUCTION}

Vertebrate-dispersed plants are faced with a challenging set of tasks. Fruits and seeds have to attract seed dispersers, protect developing embryos, and deter seed predators and pulp thieves (Herrera 1982, Cipollini and Levey 1997). These functions are not always independent, and are mediated by both physical and chemical properties of fruits and seeds, acting before, during, and after dispersal (Herrera 1986, 1998, Schupp 1995, Levey et al. 2007). The physical structure of seed coats, for example, must be strong enough to resist damage in the

Manuscript received 14 March 2007; revised 24 May 2007; accepted 29 May 2007. Corresponding Editor: M. D. Dearing.

5 E-mail: tewksjj@u.washington.edu gut of seed dispersers during dispersal and porous enough to imbibe water and allow germination after dispersal (Barnea et al. 1991, Traveset 1998, Baskin and Baskin 2001, Traveset et al. 2007, 2008). Likewise, fruit chemistry must also be multifunctional, playing different roles as seeds mature and are consumed and dispersed (Cipollini 2000). Less often considered is the fact that chemical and physical traits of fruits and seeds may act in concert to mediate the dispersal process, and these interactions themselves may shift temporally and taxonomically. Such shifts in the function of fruit and seed traits are often overlooked because most studies of fruitfrugivore interactions focus on a single type of interaction at a particular stage of the plant's life cycle (Levey et al. 2007). Understanding the evolutionary and 
ecological impacts of fruit and seed phenotypes will require synthetic approaches that consider the role of fruit characters from biosynthesis through germination, and that explicitly examine interactions between traits in a comparative context.

The vast majority of studies on the significance of fruit and seed traits have focused on pre-dispersal interactions, such as predation and fruit choice, or on postdispersal interactions, such as seed predation and dormancy (Willson and Whelan 1990, Jordano 1992, Hulme and Benkman 2002, Alcántara and Rey 2003, Baraloto et al. 2005) Surprisingly little work has examined the significance of fruit traits for the dispersal process itself, even through mediation of seed retention in frugivore guts can have strong fitness consequences for plants and is accomplished through seed and fruit traits (Izhaki and Safriel 1990, Murray et al. 1994, Traveset and Verdú 2001, Tsahar et al. 2003, Traveset et al. 2007, 2008). Much of this mediation may be accomplished by variation in fruit chemistry, which can either slow or speed the time a seed remains in the gut of its disperser, hereafter called "retention time" (Wahaj et al. 1998). Changes in retention can impact plant fitness in at least two ways: by changing the spatial distribution of dispersed seeds or by changing their physical condition. Here we focus on seed condition because retention-mediated changes in seed condition place strong limits on potential distribution-related benefits: If seed viability declines steeply with increased retention time, any distribution-related benefits to longer retention times will make little difference.

We use a comparative context to examine chemical mediation of seed dispersal in wild chilies. The primary metabolites responsible for the heat in chilies are capsaicinoids. Previous work on the significance of these compounds has focused on pre- and post-dispersal benefits, which are generally related to protection (Tewksbury et al. 1999, Tewksbury and Nabhan 2001). We focus on the dispersal process itself, addressing three questions in a series of intra- and interspecific comparisons using two Capsicum species. (1) Does capsaicin affect gut retention time of seeds in the avian consumers of chili fruits? (2) How does variation in gut retention time influence viability and germination in defecated seeds? (3) Is the relationship between gut retention time and seed viability influenced by basic morphological characteristics of seeds?

\section{Methods \\ Study systems}

Capsicum chacoense Hunz is one of four ancestral species of Capsicum (Walsh and Hoot 2001), and is endemic to the Chaco region of eastern Bolivia, western Paraguay, and northern Argentina. The plant ranges from 0.3 to $1.5 \mathrm{~m}$ in height and produces fruit from March through May. A sample of one ripe fruit per plant from 95 plants at our primary study site $\left(19^{\circ} 46^{\prime} \mathrm{S}\right.$, $\left.62^{\circ} 42^{\prime} \mathrm{W}\right)$, shows that fruits average $9.55 \pm 0.16 \mathrm{~mm}$ (mean $\pm \mathrm{SE}$ ) in length, and $5.70 \pm 0.05 \mathrm{~mm}$ in width and contain an average of $17.8 \pm 0.52$ seeds (mean \pm SE, range $=4-26$ ). Fruits are most often consumed by Short-billed Elaenias (Elaenia parvirostris; hereafter "elaenia"), which consume fruits whole and do not regurgitate seeds (Levey et al. 2006). At our primary study site, elaenias accounted for nearly $50 \%$ of total fruit consumption (Levey et al. 2006). Throughout much of its range in Bolivia, C. chacoense is polymorphic for pungency; some plants produce highly pungent fruit with up to $1.5 \%$ fruit dry mass in capsaicinoids, whereas others are non-pungent, producing fruits that completely lack capsaicinoids. Fruits from pungent and nonpungent plants are nutritionally very similar (Levey et. al. 2006), and are so similar morphologically that the only way to tell them apart in the field is to consume the fruit.

Capsicum annuum L. var. glabriusculum (Dunal) Heiser \& Pickersgill. is the most derived wild species of Capsicum (Walsh and Hoot 2001), and grows in a wide range of habitats from northern South America through southern Arizona, reaching its highest density in arid mid-elevation regions in the state of Sonora, Mexico (Perramond 2005). At our southern Arizona study site at $31^{\circ} 33^{\prime} \mathrm{N}, 111^{\circ} 4^{\prime} \mathrm{W}$ (for details, see Tewksbury et al. 1999), C. annuum bears ripe fruit from August through January. Its fruits are $4-8 \mathrm{~mm}$ in diameter and contain 8-10 seeds in southern Arizona (range 2-15 seeds; Bronstein et al. 2007); all individuals produce only pungent fruit. At our primary study site, the most common consumer of $C$. annuum is the Curve-billed Thrasher (Toxostoma curvirostre; hereafter "thrasher"), which consumes fruits whole, does not regurgitate seeds, and is responsible for $69 \%$ of consumed fruits (Levey et al. 2006).

\section{Effect of capsaicin on gut retention time}

Experiments on elaenias were conducted in Bolivia and experiments on thrashers were conducted in Arizona. In both places, birds were housed in separate cages $(0.5 \times 0.4 \times 0.5 \mathrm{~m})$ and were maintained on a fruitbased diet (Denslow et al. 1987), provided ad libitum and supplemented with mealworms. On trial days, birds were given their maintenance diet from dawn until 08:00 hours, when it was removed for 10 minutes. This brief period of fasting approximated the normal time between feeding bouts and helped to assure that birds would eat at the start of the trial, thereby standardizing gut fullness, an important determinant of retention time in fruit-eating birds (Levey et al. 1999). Elaenias immediately consumed chilies after the fast, but because thrashers did not, we resorted to force-feeding them. To test whether force-feeding influenced thrasher retention times, we ran a separate set of trials and compared seed retention times of force-fed and nonforce-fed birds, using a paired design and including only non-force-fed birds that consumed two or three fruits within 3 minutes after the 10-minute fast. There was no 
effect of force-feeding on gut retention time ( $t=0.21, n=$ 10 individuals, $P=0.84$ ).

Because we needed to tightly control capsaicin concentrations and eliminate possible variation in all other secondary metabolites, we based all retention time trials on non-pungent $C$. chacoense fruits that we injected with either capsaicin or a control solution. Although thrashers do not consume $C$. chacoense fruits in nature, the color, nutritional content, fruit size, and seed size of $C$. chacoense and $C$. annuum fruits are very similar (Levey et al. 2006). "Pungent" fruits were injected with $10 \mu \mathrm{L}$ of a solution made by dissolving capsaicin (Sigma M2028; Sigma-Aldrich, St. Louis, Missouri, USA) in 2-3 $\mu \mathrm{L}$ of ethanol and diluting 1:19 with water. Injections were performed with a micropipet through the hole left from abscission of the fruit from the petiole, the same location where capsaicin is produced in developing fruit. Pungent fruits fed to elaenias each contained $0.39 \mathrm{mg}$ capsaicin and those fed to thrashers contained $0.59 \mathrm{mg}$, approximating the pungency of Capsicum fruits naturally consumed by those species. Control fruits were injected with an identical solution that lacked capsaicin. Elaenias typically consume only one chili per foraging bout (only one chili was taken in 26 of 34 observed foraging bouts; Levey et al. 2006). We thus fed elaenias one fruit per trial. For thrashers, the median number of chili fruits consumed per foraging bout was three ( $n=8$ foraging bouts; Levey et al. 2006). We thus fed thrashers three fruits per trial. Because thrashers weighed, on average, $72 \mathrm{~g}$ at the beginning of trials and elaenias weighed only $14 \mathrm{~g}$, the doses of capsaicin that each species received per foraging bout (and per trial in these experiments) form similar ratios to body mass: $0.025 \mathrm{mg} / \mathrm{g}$ in thrashers and $0.027 \mathrm{mg} / \mathrm{g}$ in elaenias.

On the first day a bird was tested, a coin flip determined whether the bird received a fruit with or without capsaicin. On the following day, it received the opposite type of fruit (both fruits for a given set of trials were always taken from the same non-pungent chili plant). We completed paired trials on 27 elaenias and 19 thrashers. During trials, birds had continuous access to the maintenance diet, allowing them to maintain a full gut. We observed birds continuously through one-way mirrors for the first three hours of a trial, during which time we recorded the time of each defecation and removed sheets of newspaper from the bottom of the cage every $10-15$ minutes, counting seeds in each defecation. After 3 hours, we stopped continuous observations but continued to pull sheets and count seeds every 10-15 minutes for another hour. After 4 hours, we pulled sheets every 30 minutes until 18:00 hours, approximately 15 minutes before complete darkness. Finally, we checked sheets the following morning for any seeds defecated during the night. We recorded retention time of each seed to the nearest minute for the first 3 hours. After that, we used the midpoint between sheet removal times to estimate retention times. For the few seeds defecated during the night $(0.7 \%$ of 1370 seeds for elaenias and $1.6 \%$ of 1511 seeds for thrashers), defecation time was calculated as the midpoint between the last sheet removal and complete darkness, providing a conservative estimate of retention times for the last seeds defecated. Changing this calculation to the midpoint of the night interval does not change our results.

\section{Effect of retention time on seed germination}

All trials were performed with the primary consumers of chilies in each system: elaenias consuming naturally pungent and non-pungent $C$. chacoense, and thrashers consuming naturally pungent $C$. annuum. To collect gutpassed seeds for germination, we removed seeds from defecations of known time intervals, using the same protocol just detailed. We germinated seeds from 32 trials per $C$. chacoense chili type (pungent and nonpungent, fruits taken from eight pungent and eight nonpungent plants), using 15 different elaenias. Because $C$. chacoense seeds typically overwinter from time of dispersal (March-May) to the start of the rainy season (October-November), we stored seeds in a ventilated cage at our field site from the end of feeding trials (May) through October. In November, we placed seeds on cellulose pads in Petri dishes in an environmental chamber set using 5-year averages for November from a weather station near our study site (humidity $82 \%$, mean high $32.5^{\circ} \mathrm{C}$, mean low $22^{\circ} \mathrm{C}, 13 \mathrm{~h}$ light, $11 \mathrm{~h}$ dark). All seeds in a given Petri dish were from the same defecation (1231 seeds on 666 dishes); seeds were checked daily and removed upon germination. After 60 days, when germination had slowed to less than one germinant per week, all seeds were removed and checked for viability by slicing the seed and staining with tetrazolium (Cottrell 1947).

For $C$. annuum seeds, we conducted two germination experiments: a long germination experiment, as wild $C$. annuum can exhibit substantial dormancy, and a shorter experiment. In 2002, we monitored seeds from a total of seven trials, using four thrashers and fruits from seven different chili plants, for 185 days, after which we checked seeds for viability using the same tetrazolium protocol used for $C$. chacoense seeds (a total of 493 seeds placed in 122 pots, all seeds in a given pot from the same defecation). In 2005, we ran the shorter germination experiment (50 days) to increase the number of birds used and to verify effects of extended retention times on germination and viability. For this experiment, we monitored seeds from a total of 23 trials using six thrashers and 10 different chili plants. Germination trials on $C$. annuum seeds were conducted without cold stratification, as fruit removal takes place in SeptemberNovember in Arizona, and seedlings are typically coincident with winter rains, December-February. For these trials, we used a mix of potting soil and vermiculite, and placed pots in a humidity tent with natural variation in day length. As in the other 
experiments, all seeds in each pot came from the same defecation (561 seeds in 157 pots). In both experiments, all seeds were checked for viability after the end of the experiment, as previously described.

\section{Seed morphology}

Our primary interest in seed morphology was to determine the extent to which investment in physical protection of seeds mediated the effects of seed retention on germination and viability. Because seed coats are most vulnerable to scarification damage at their thinnest points, we measured the average minimum seed coat thickness of pungent and non-pungent $C$. chacoense and pungent $C$. annuum seeds. To minimize environmental effects on seed morphology, all fruits were from plants grown under identical greenhouse conditions. A single ripe fruit was randomly selected per plant, and a single seed was randomly selected from the fruit for measurement. Seeds were dried, sectioned, and photographed. We imaged each section and calculated minimum seed coat thickness as the mean of 10 measurements per seed, five on each side, taken at the thinnest points on each side of the seed. All measurements were made using Image J (Rasband 1997-2006). We averaged these 10 measurements for each seed and used this as a measure of seed coat thickness at the most vulnerable parts of the seed. Finally, in another set of 23 trials (using the same 10 plants), we removed 1-2 seeds from C. annuum fruits through a small slit placed in a random location on the fruit before feeding them to thrashers. These seeds served as randomly selected "control" seeds, as all seeds in a chili fruit are accessible from the outside of the fruit. After trials, seeds from defecations of known time were gently wiped clean and individually weighed. To determine whether gut passage reduces seed mass, the mass of defecated seeds was compared to the mass of seeds removed before ingestion.

\section{Analyses}

To explore capsaicin effects on gut retention times of seeds in C. chacoense fruits with and without capsaicin, we conducted two analyses. First, we calculated mean seed retention time as $\Sigma f_{i} t_{i}$, where $f_{i}$ is the proportion of total ingested seeds excreted at time $t_{i}$ (Levey and Karasov 1992). We used a paired design for all analyses; thus we first calculated the difference in retention times for the same bird fed control fruits and fruits containing capsaicin, and we checked the distribution of these differences for deviation from normality. Finding none, we used paired $t$ tests to compare mean retention between control trials and trials in which capsaicin was added to the fruit. After this analysis, we explored the timing of capsaicin effects on gut retention. To do this, we first plotted the cumulative frequency distribution of seeds defecated as a function of time for trials with and without capsaicin. If capsaicin effects are immediate, we should see differences in these distributions beginning with the first seeds. Alternatively, if capsaicin effects are delayed, the timing of the effect should be indicated by the point at which cumulative seed defecation changes between trials with and without capsaicin. Our plots indicated a delayed effect (Fig. 1A), and we used the plots to estimate the timing of the capsaicin (Fig. 1A; 70-100 min), and conducted paired tests at two time intervals: 60 minutes, which is before the point of divergence in both species, and 110 minutes, which is after this point in both species. After checking for deviations from normality, we used paired tests for thrashers and Wilcoxon signed rank tests for elaenias. If we correctly identified the point at which capsaicin changes retention, we should find no significant difference in the proportion of seeds defecated at 60 minutes, but a strong difference at 110 minutes for both species. We used one-tailed $P$ values for these comparisons because directionality was already determined by the first test, and we corrected for multiple tests per species using sequential Bonferroni adjustments (Rice 1989).

To examine the effect of gut retention time on the proportion of germinated seeds and the total proportion of seeds that were viable at the end of these trials ((germinated seed + viable ungerminated seed)/total), we used logistic regression. We examined the effect of time in the digestive tract ("retention time"). For $C$. chacoense, we included the following categorical covariates: individual bird, individual fruit, and location of seeds in the environmental chamber (dishes were not rotated, and chambers do not have uniform heating throughout). For $C$. annuum, there was no location factor because germination was conducted in pots that were rotated, and no fruit factor because defecated seeds could not be assigned to individual fruits.

To build models, we followed Hosmer and Lemeshow (2000), first evaluating retention time and potential covariates in univariate analyses (chi-square tests for categorical covariates, two-sample $t$ test for retention time), and including only those variables with $P$ values $<0.25$. We began with full models that lacked interaction terms, and evaluated the contribution of retention time and all covariates to observed results using likelihood ratio tests. In particular, we examined change in -2 log-likelihood between models (Norusis 2003) and compared Wald statistics for models with and without each potential variable. Retention time, the only continuous variable, was checked for deviation from linearity of the logit, and was transformed as necessary. Interaction terms were considered after the modelbuilding stage, and were included only if the coefficient $P$ value was $<0.05$. Differences in overall germination rates between pungent and non-pungent $C$. chacoense seeds were examined using paired $t$ tests, pairing each treatment within each bird.

To examine the effect of gut retention on the time from planting to germination (germination rate), we used the mean time to germination for all seeds in each defecation as a dependent variable, and after examining error distributions and variance: mean ratios, we tested 


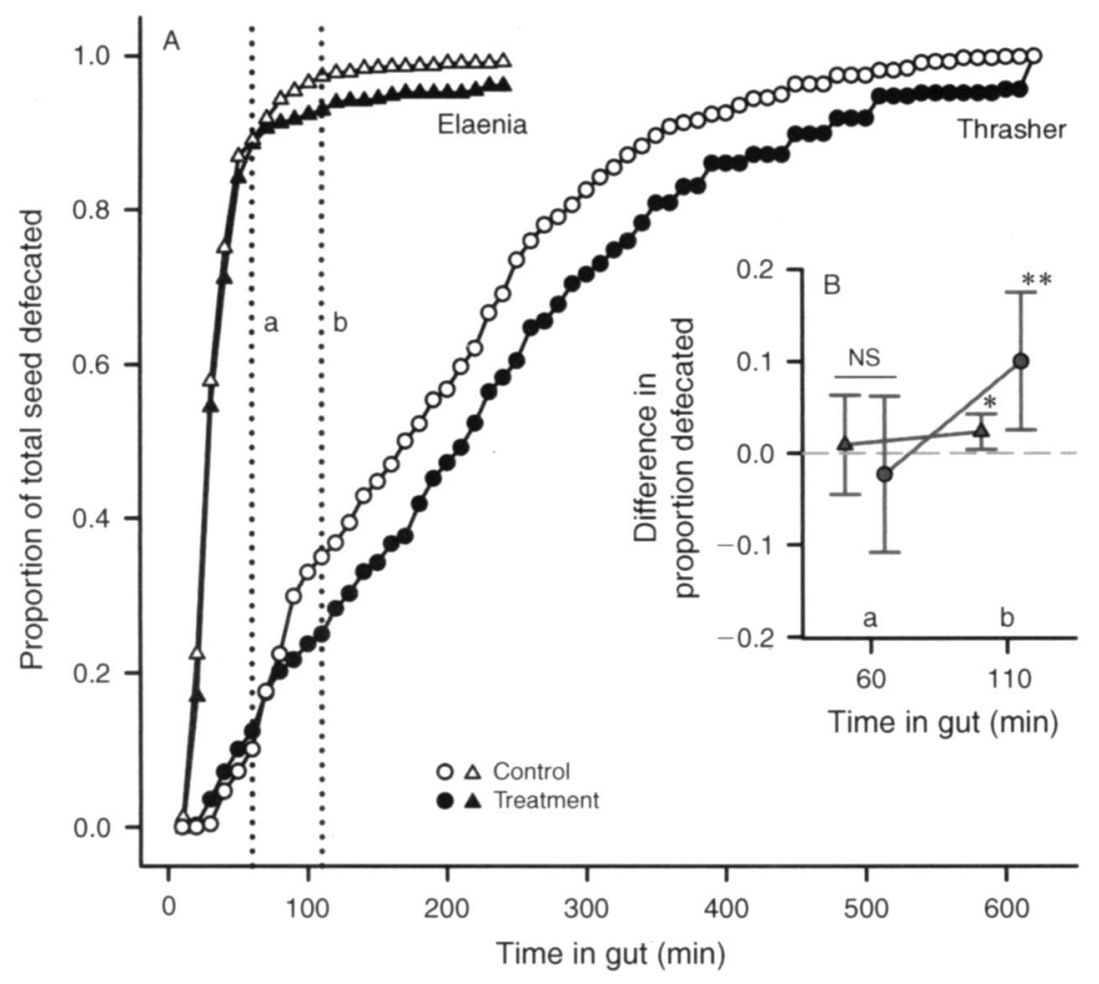

Fig. 1. (A) Cumulative frequency distribution of seeds from control fruit (no capsaicin) and treatment fruit (capsaicin injected) eaten and defecated by elaenias (triangles) and thrashers (circles). Error bars are not shown as they obscure the differences between curves, and all tests are paired, blocking on bird. The dotted vertical reference lines indicate the points before (a, $60 \mathrm{~min})$ and after (b, $110 \mathrm{~min}$ ) the observed divergence in defecation rate between trials with and without capsaicin. (B) The inset shows the difference in the proportion of seeds defecated at each reference point (mean and 95\% CI) for elaenias (triangles) and thrashers (circles), with positive differences indicating proportionately more seeds defecated during control trials compared to trials with capsaicin. No significant differences were detected at $60 \mathrm{~min}$ (all $P>0.5$ ), but at $110 \mathrm{~min}$, after seed ingestion, both elaenias and thrashers had defecated significantly more of the seeds during control trials compared to treatment trials $\left({ }^{*} P<0.05 ;{ }^{* *} P<0.01\right)$.

the effects of time in the digestive tract using generalized linear models (GLM) with gamma error distributions. We used $F$ tests on difference in residual deviance for model simplification (Crawley 2002). For C. chacoense, we log-transformed gut retention to allow better parameter estimation and to minimize variance in the error distribution, and we included seed type (pungent or non-pungent) as a fixed factor.

To examine differences in seed coat thickness between seed types, we used ANOVA, as these data were normally distributed (Kolmogorov-Smirnov $Z=0.91$, $P>0.35$ ). To compare between seed types, we used Bonferroni-adjusted post hoc tests. To examine the effects of seed retention on seed mass, we used a generalized linear mixed model (GLMM), blocking by fruit for all trials. We conducted two tests, the first, examining seed mass of defecated seeds as a function of retention time, and the second comparing average seed mass of defecated vs. control seeds removed from the fruit before fruit were fed to the thrashers.

All analyses were conducted using S-Plus version 6.2 or SPSS version 11.05. All errors presented in the text and graphics are standard errors (SE) unless otherwise noted.

\section{RESUlts}

Capsaicin and gut retention

Seed retention times of elaenias and thrashers were very different. Mean retention time of control (nonpungent) seeds averaged $38 \pm 4 \mathrm{~min}$ for elaenias and 190 $\pm 11 \mathrm{~min}$ for thrashers (Fig. 1A). Capsaicin caused significant increases in seed retention times for both species (elaenias' average increase $=15 \%$ of mean retention time, difference $=10 \pm 5 \mathrm{~min}$, paired $t_{1,26}=$ 2.18, $P=0.039$; thrashers' average increase $=20 \%$, difference $=42 \pm 19 \mathrm{~min}$, paired $t_{1,18}=2.19, P=0.042$ ) In addition, the effect of capsaicin on gut retention time was not distributed evenly. In both species, at $60 \mathrm{~min}$ after seed consumption, the same proportion of seeds were passed in control and treatment trials (thrashers, paired $t_{1,18}=0.57, P>0.5$; elaenias, $Z=0.24, P=0.4$ ), but both species showed significantly fewer seeds defecated at 110 minutes (thrashers, paired $t_{1,18}=2.8$, $P=0.006$; elaenias, $Z=2.2, P=0.014)$, suggesting that capsaicin impacts begin $70-100$ min after seed ingestion for both species.

In elaenias, capsaicin's slowing of gut passage resulted in a large increase in the range of seed retention times 
(time of last seed defecated minus time of first) from control trials to capsaicin trials $(78 \pm 17 \mathrm{~min}$ vs. $143 \pm$ 34 min, respectively; $t_{1,26}=2.4, P=0.026$ ). In thrashers, the constipative effects of capsaicin increased seed retention times without altering the overall range of retention for a given trial (last seed - first seed, without capsaicin $=419 \pm 21 \mathrm{~min}$, and with capsaicin $=416 \pm 17$ min; paired $\left.t_{1,18}=-0.2, P=0.847\right)$.

\section{Seed germination and viability}

The effects of seed retention on germination and seed viability varied both within $C$. chacoense seed types (pungent vs. non-pungent), and between Capsicum species. In pungent and non-pungent $C$. chacoense, virtually all of the viable seed germinated before the end of the trials (only six ungerminated seeds passed viability tests); thus we report data for germination only. In contrast, $55 \%$ of ungerminated C. annuum seeds were viable after 50 days, and $35 \%$ were still viable after 185 days. Thus, for $C$. annuum we examine effects of gut retention on both total viability and germination probability.

Non-pungent $C$. chacoense seeds showed no consistent effect of retention time on germination (Fig. 2A, Table 1; $P=0.76$ ); seeds retained in elaenia guts for $>200 \mathrm{~min}$ were as viable as those defecated much earlier (Fig. 2A). Pungent $C$. chacoense seeds, in contrast, showed significant declines in germination as a function of retention time (Fig. 2B, Table 1; $P=0.0008$ ), with $80 \%$ germination for seeds with retention times of $<30 \mathrm{~min}$, $65 \%$ germination for seeds in the gut $120-180 \mathrm{~min}$, and $45 \%$ germination for seeds in the gut for $>180 \mathrm{~min}$.

In $C$. annuum, the proportion of seeds defecated by thrashers that germinated after 50 days and after 185 days increased as a function of time in the digestive tract (Fig. 2C, D), and the increase in odds of germinating as a function of gut retention was indistinguishable across the two trials (odds ratio $=1.002$; Table 1 ). Importantly, while retention time had consistent, positive effects on germination, it had little effect on seed viability (all $P>$ 0.05; Table 1, Fig. 2C, D); $97 \%$ of seeds remaining in the digestive tract of thrashers for $>11$ hours were viable after 50 days, and $83 \%$ were still viable after 185 days. When we examined the effect of gut retention on overall seed viability, we found no relationship (regression coefficient $B=0.001, P=0.132$ ), suggesting that the positive relationship between retention time and germination was due to seed scarification.

Germination rate (average time to germination) showed no significant relationship with time in the digestive tract in either system. Although $C$. chacoense showed weak, nonsignificant interactions with time in the digestive tract of elaenias $(B=-0.95 \ln$ (minutes in gut), $F_{1,505}=1.65, P=0.20$ ), germination rate of $C$. annuum showed no relationship with time in the digestive tract of thrashers $\left(B<0.0001\right.$ minutes in the gut; $F_{1,75}=$ $0.39, P=0.0 .53)$. Germination rate was significantly slower in non-pungent than in pungent $C$. chacoense (mean time to germination $29.3 \pm 1$ day for non-pungent vs. $24.8 \pm 1$ day for pungent seeds, $n=421$ and 485 , respectively; $F=36.3, P<0.0001$ ), and germination rate for $C$. annuum averaged $19.1 \pm 0.7$ days.

\section{Seed coat thickness and seed mass}

Seed coats differed significantly among seed types (Fig. 3A; $F_{2,89}=3.5, P=0.036$ ). Non-pungent $C$. chacoense seed coats were $12 \%$ thicker than pungent $C$. chacoense seed coats (mean difference $4.2 \mu \mathrm{m}, P=0.01$ ). $C$. annuum seed coats were almost identical in thickness to non-pungent $C$. chacoense seed coats (mean difference $0.6 \mu \mathrm{m}, P=0.7)$.

After controlling for differences in seed mass among fruits (all Wald $Z>2.6$, all $P<0.008$ ), $C$. annuum seed mass declined linearly with retention time (Fig. 3B; $F_{1,209}=46.8, P<0.0001$ ), suggesting either that lower germination rates associated with longer time in the gut were mediated by thinning of the seed coat during gut passage, or that retention time changes seed coat permeability. The effect of retention time on seed mass was not due to seed sorting within the digestive tract, because control seeds removed before consumption were significantly heavier than seeds from the same fruit that passed through the digestive tract (Fig. 3C; $F_{1,406}=34.2$, $P<0.0001$ ). Ingestion of seeds resulted in an average reduction in seed mass of $0.37 \pm 0.06 \mathrm{mg}$, or $9.5 \%$ of original seed mass.

\section{DisCUSSION}

We found that capsaicin has a consistent constipative effect on the two bird species that we studied, but its effects are not immediate: it significantly slows passage of seeds that remain in the gut longer than $\sim 80$ minutes, but does not affect retention of seeds that are passed before then. These results were consistent across two unrelated bird species on different continents. Because the mechanism of action is unknown, it is difficult to speculate on the reason for the consistency in the timing of capsaicin effects across species. Regardless of mechanism, this lag in the effects of capsaicin has two important implications. First, because capsaicin has the potential to increase both the mean and variance in seed retention time, seeds may be moved longer distances and scattered more widely (Murray et al. 1994), potentially increasing the opportunity for long-distance dispersal and reducing the likelihood of dispersal limitation (Nathan and Muller-Landau 2000, Clark et al. 2003). Second, effects of fruit secondary compounds on seed retention times may be difficult to detect if experimental trials are not sufficiently long. Previous studies on gut retention times have emphasized the first 1-2 hours after ingestion because most seeds are typically defecated then (Johnson et al. 1985, Levey and Grajal 1991, Murray et al. 1994, Wahaj et al. 1998, Stanley and Lill 2002). Some common metrics of retention time (e.g., transit time and mode) will be insensitive to the type of effect that we found for capsaicin. 


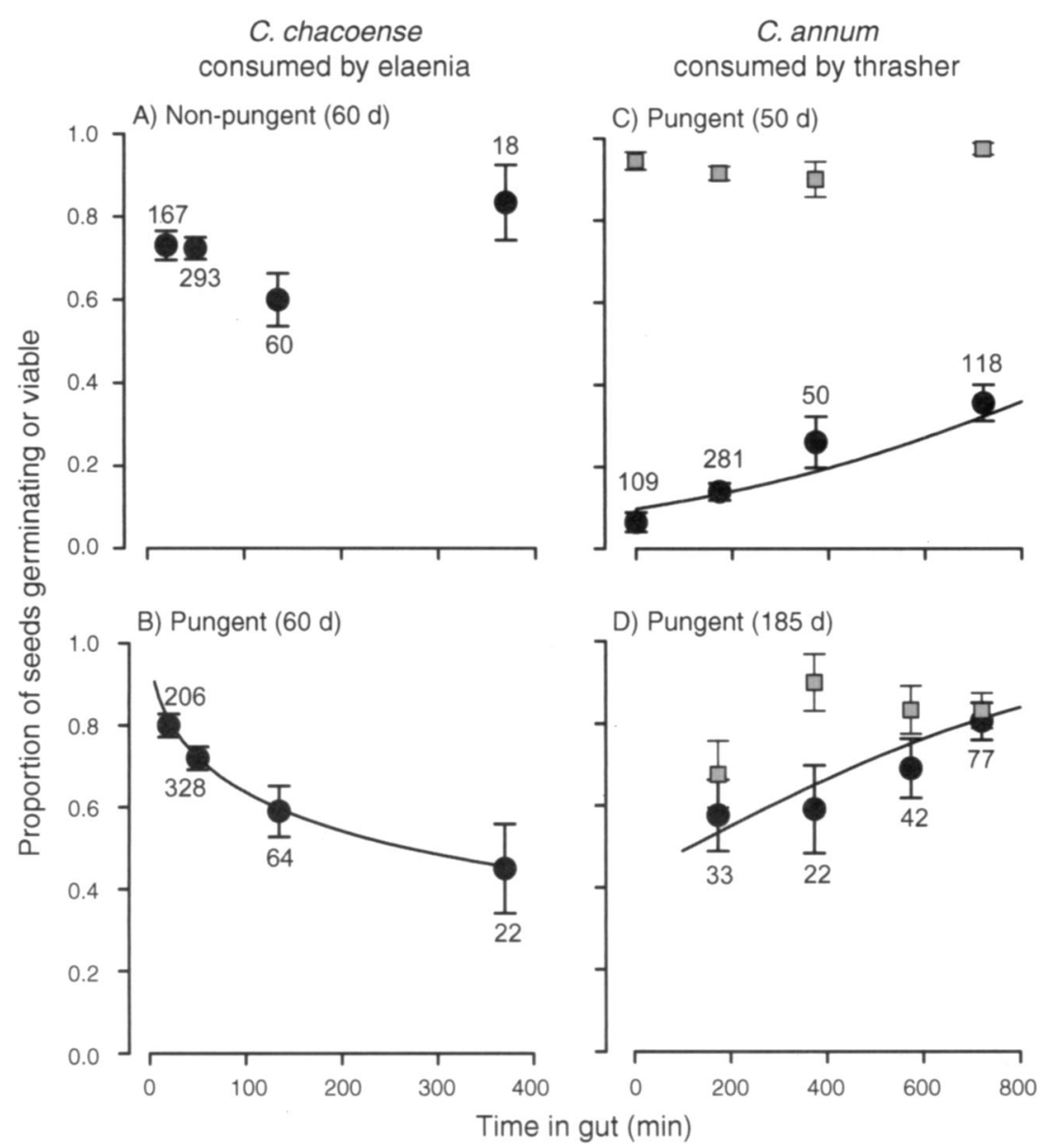

FIG. 2. Effects of gut retention on seed germination and viability for non-pungent and pungent Capsicum chacoense after 60 days $(\mathrm{A}$ and $\mathrm{B})$ and pungent Capsicum annuum after 50 days and 185 days ( $\mathrm{C}$ and $\mathrm{D})$. Black circles indicate the proportion of seeds germinating within the trial period; gray squares indicate the proportion of seeds viable (germinants + viable seeds yet to germinate) at the end of the trial period; values are means \pm SE. Only six of $1158 \mathrm{C}$. chacoense seeds were viable; thus the proportion germinating and viability are indistinguishable. Sample sizes (number of seeds defecated in a given time interval) are given beside symbols. Intervals are shown for clarity of presentation; analyses were conducted using actual time in the digestive tract. Lines indicate predicted germination probability based on logistic regression for pungent $C$. chacoense and C. annuum (50- and 185-day trials. Non-pungent $C$. chacoense and viability of $C$. annuum showed no significant relationship (see Table 1). Retention times for $C$. chacoense were log-transformed to linearize the logit (see Methods). Intervals used for C. chacoense were based on a $\log$ scale (8-29, $29-81,81-221$, and $>221 \mathrm{~min})$. Intervals used for $C$. annuum were based on a linear scale $(30-274,275-474,474-674$, and $>674$ min). In the 50-day trial, germination and viability of control seeds taken directly from fruit are also shown (at the 0 point). All symbols are plotted at midpoints for data in each interval.

More generally, our results underscore the importance of looking beyond seemingly straightforward effects of secondary metabolites. Any dispersal-related benefits to longer and more variable seed retention times may be trumped by simultaneous effects of longer retention on seed condition. Also, the effects of capsaicin on seed condition vary in sign and intensity with differences in gut physiology of the primary consumers and with differences in the morphology of the seeds themselves.

\section{Capsaicin effects in $\mathrm{C}$. chacoense}

Seeds from pungent $C$. chacoense plants have thinner seed coats than seeds from non-pungent plants and suffer large reductions in germination associated with increased retention times. Thus, the constipative effects of capsaicin should have strong negative impacts on the condition of pungent $C$. chacoense seeds. Yet, because elaenias, the major disperser of $C$. chacoense, pass seeds rapidly, the constipative effects of capsaicin affected only a small fraction of the seeds in our trial. Elaenias passed $93 \%$ of ingested seeds before 80 minutes, leaving little opportunity for direct effects of capsaicin on most seeds. The largest effect of capsaicin on retention in elaenias was an increase in the variance in retention times, with seeds from a single fruit passing through the gut over a 2-3 hour period when capsaicin was added. It is difficult to know whether such increases in the range of retention times are beneficial or detrimental for these 
TABLE 1. Logistic regression models for germination and viability of Capsicum chacoense and C. annuum seeds after passage through bird guts.

\begin{tabular}{|c|c|c|c|c|c|c|}
\hline Variable & $B$ & SE & Wald $Z$ & $\mathrm{df}$ & $P$ & $\operatorname{Exp}(B)$ \\
\hline \multicolumn{7}{|c|}{ A) Germination: non-pungent $C$. chacoense, 60 -day trial: $\chi^{2}=127, P<0.001$} \\
\hline Constant & 0.9851 & 0.148 & 44.014 & 1 & $<0.0001$ & 2.6778 \\
\hline $\ln ($ retention time $)$ & 0.0630 & 0.2020 & 0.096 & 1 & 0.7567 & 1.0646 \\
\hline Fruit & & & 10.790 & 8 & 0.2139 & \\
\hline Bird & & & 35.581 & 13 & 0.0007 & \\
\hline Location & & & 44.350 & 6 & $<0.0001$ & \\
\hline \multicolumn{7}{|c|}{ B) Germination: pungent $C$. chacoense, 60 -day trial: $\chi^{2}=114, P<0.001$} \\
\hline Constant & 3.2795 & 0.6390 & 26.336 & 1 & $<0.0005$ & 26.5599 \\
\hline $\ln ($ retention time $)$ & -0.5635 & 0.1680 & 11.249 & 1 & 0.0008 & 0.5692 \\
\hline Fruit & & & 22.529 & 9 & 0.0073 & \\
\hline Bird & & & 30.769 & 14 & 0.0060 & \\
\hline Location & & & 25.994 & 6 & 0.0002 & \\
\hline \multicolumn{7}{|c|}{ C) Germination: pungent $C$. annuum, 50-day trial: $\chi^{2}=92.7, P<0.001$} \\
\hline Constant & -2.909 & 0.1832 & 251.997 & 1 & $<0.0005$ & 0.055 \\
\hline Retention time & 0.0020 & 0.0003 & 251.997 & 1 & $<0.0005$ & 1.0020 \\
\hline Bird & & & 51.223 & 5 & $<0.0005$ & \\
\hline \multicolumn{7}{|c|}{ D) Germination: pungent $C$. annuum, 185-day trial: $\chi^{2}=18, P=0.001$} \\
\hline Constant & -0.2855 & 0.4804 & 0.353 & 1 & 0.552 & 0.7516 \\
\hline Retention time & 0.0024 & 0.0008 & 8.779 & 1 & 0.0030 & 1.0024 \\
\hline Bird & & & 14.161 & 3 & 0.0027 & \\
\hline \multicolumn{7}{|c|}{ E) Viability: pungent $C$. annuum, 50-day trial: $\chi^{2}=14.6, P=0.024$} \\
\hline Constant & 2.3264 & 0.2122 & 120.997 & 1 & $<0.0005$ & 10.2332 \\
\hline Retention time & 0.0007 & 0.0004 & 2.926 & 1 & 0.087 & 1.001 \\
\hline Bird & & & 9.868 & 5 & 0.079 & \\
\hline \multicolumn{7}{|c|}{ F) Viability: pungent $C$. annuum, 185-day trial: $\chi^{2}=9.1, P=0.059$} \\
\hline Constant & 5.6187 & 000 & 0.000 & 1 & 0.998 & 275.541 \\
\hline Retention time & 0.0013 & 0.0009 & 2.267 & 1 & 0.132 & 1.001 \\
\hline Bird & & & 2.157 & 3 & 0.541 & \\
\hline
\end{tabular}

Notes: Germination probability (A-D) for non-pungent and pungent $C$. chacoense (A, B; 60-day trials) after passing through the gut of elaenias and for pungent $C$. annuum at 50 days (C) and 185 days (D) after passing through the gut of thrashers. Regression models for C. annuum seed viability (gut-passed germinated seed + gut-passed viable seed yet to germinate) at 50 and 185 days (E, F) are also shown. Viability and germination were virtually identical for $C$. chacoense, so data are not shown. Model $\chi^{2}$ measures the difference between the likelihood of obtaining the observed results under the final model and the null model. $B$ is the regression coefficient for each effect, representing the change in the log odds of germination probability with a one-unit change in the independent variable. $\operatorname{Exp}(B)$ represents the change in actual odds of germination with a one-unit change in the independent variable. Fruit, bird, and location are categorical covariates. Coefficients and odds vary by individual, but are excluded to simplify presentation, as individual identity does not affect model interpretation.

seeds, as Capsicum plants must balance the benefit of rare long-distance dispersal events against the cost of seed damage among seeds that are retained in the gut for long periods.

The degree to which capsaicin affects gut retention time probably depends on how many chilies elaenias consume per day. Elaenias are by far the most common consumers of chilies in all of our Bolivian study populations (Levey et al. 2006, Tewksbury et al. 2006), and the extent of diet mixing may be a function of the availability of chilies and the frequency of pungent plants in the population. At our primary study site, chili plants are rare and their fruit make up no more than 1$2 \%$ of the fruit biomass available to birds (Tewksbury et al. 2006; J. J. Tewksbury, unpublished data). Further, $>60 \%$ of the plants in the population lack capsaicin (Tewksbury et al. 2006). In this ecological context, elaenias mix their diet heavily, and the few pungent fruits that are consumed are unlikely to be affected by capsaicin consumed during a previous bout. In contrast, in dense populations where all plants are pungent
(Tewksbury et al. 2006), elaenias may eat many chilies in a day, and if the constipative effects accumulate between foraging bouts, this could increase the effect of capsaicin on gut retention.

\section{Capsaicin effects in C. annuum}

In contrast to $C$. chacoense, the way in which capsaicin in $C$. annuum fruit interacts with seed morphology and disperser physiology suggests net benefits for the plants. Gut passage in thrashers is sufficiently slow for most seeds to be affected by capsaicin (79\% of seeds were passed after 80 minutes), and the extended retention times caused by capsaicin were substantial: an addition of almost 45 minutes in average seed retention time. This added retention appeared to benefit $C$. annuum seeds, because increased retention time resulted in a higher proportion of seeds germinating, with no effect on overall seed viability. We interpret the increased proportion of germinating seeds and the uniformly high viability as evidence that extended retention caused more seeds to break dorman- 
cy and to germinate more rapidly, once moisture cues were provided (Traveset et al. 2007). These effects are consistent with our finding that $C$. annuum seed coats are relatively thick (compared to pungent $C$. chacoense seeds) and the finding that the mass of defecated $C$. annuum seeds is negatively correlated with time in the gut, presumably because of seed scarification. Scarification often increases seed coat porosity, allowing seeds to respond more quickly to germination cues (Baskin and Baskin 2001), a trait that can be particularly advantageous for long-lived perennials such as Capsicum (Verdú and Traveset 2005; but see Janzen 1981, 1984)

\section{Trade-offs in chemical vs. physical protection of seeds}

In pungent chilies, gut retention is clearly influenced by fruit chemistry, but the effects of altered retention times on germination are mediated by seed coat thickness. Seeds from pungent $C$. chacoense have thin seed coats and are negatively impacted by longer retention times, whereas seeds from $C$. annuum and non-pungent $C$. chacoense have thick seed coats and are either unaffected or are positively affected by longer retention times.

We propose that capsaicin production and seed coat thickness may be biosynthetically linked in C. chacoense, such that seeds enjoy either chemical protection from capsaicin or greater physical protection from thicker seed coats. Capsaicin is a product of the phenylpropanoid pathway, which also produces lignin (Dixon and Paiva 1995). In many plants, lignin creates the structural rigidity in seed coats and thus is primarily responsible for defense against physical damage to seeds (Alvarez et al. 1997, Atanassova et al. 2004). Capsaicin, on the other hand, clearly provides chemical defense of seeds and fruit. In $C$. annuum it deters foraging by small mammals that are commonly seed predators (Tewksbury and Nabhan 2001), and in C. chacoense it protects fruits and seeds from Fusarium fungi, which attack and kill seeds (J. Tewksbury, K. Reagan, and N. Machnicki, unpublished data). This link between physical defense provided by lignin and chemical defense provided by capsaicin is noteworthy because lignin and capsaicin are likely to compete for molecular precursors. Production of capsaicin and lignin occurs coincidentally within developing chili fruits and lignin production appears to be down-regulated during the period in development when capsaicin is being synthesized (Sukrasno and Yeoman 1993). We hypothesize that the reason nonpungent $C$. chacoense seeds have thicker seed coats and are unaffected by time in bird guts is because the tradeoff between production of capsaicin and lignin is tipped in favor of lignin. Likewise, the reason pungent $C$. chacoense seeds have thinner seed coats and are often damaged in bird guts is because production of capsaicin results in fewer metabolic precursors for production of lignin.

In $C$. annuum, the trade-off between capsaicin and lignin production is not apparent: $C$. annuum seeds are
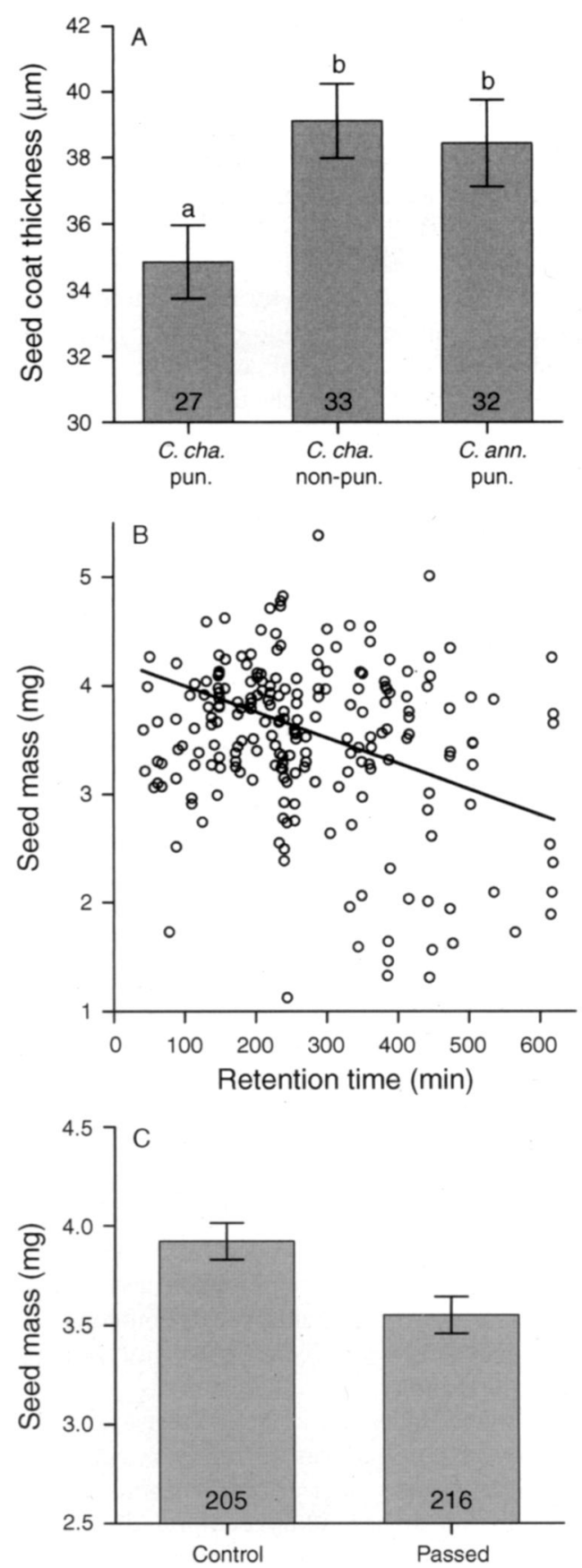

FIG. 3. (A) Minimum seed coat thickness at the thinnest point (mean $\pm \mathrm{SE}$ ) for non-pungent $C$. chacoense, pungent $C$. chacoense, and $C$. annuum seeds. Lowercase letters above bars indicate significant differences $(P<0.05)$ from Bonferroniadjusted pairwise comparisons among seed types. Sample size (number of seeds analyzed) is given at the base of each column. (B) The relationship between seed mass and time in the digestive tract (retention time) for $C$. annuum seeds consumed by thrashers $\left(r^{2}=0.15, P<0.001\right)$. (C) Seed mass (mean \pm SE) for $C$. annuum seeds removed from fruit (control) and for seeds from the same fruit passed through the digestive tract of thrashers (passed) 
protected both by thick seed coats and by capsaicin. We do not know why the proposed trade-off between physical and chemical defense is apparent within, but not between, species. It is noteworthy that pungency is a derived trait (Walsh and Hoot 2001). C. chacoense is one of the most ancestral pungent chilies, with a point of origin near our study region (McLeod et al. 1982). No recently derived species are polymorphic for pungency. Presumably, the mechanism by which molecular intermediates in the phenylpropanoid pathway are shunted to production of lignin or capsaicin has become evolutionarily modified such that seeds of recently derived species can be both pungent and heavily lignified.

\section{Conclusion}

Capsaicin can be viewed as a chemical mediator of the trade-off between dispersal distance (which is positively correlated with retention time) and seed viability (which is negatively correlated with retention time), but it is best viewed in an even broader context, spanning fruit development (Sukrasno and Yeoman 1993), pre-dispersal seed predation (Tewksbury and Nabhan 2001), dispersal itself, and post-dispersal impacts (Tewksbury et al. 1999; unpublished data). Fruit and seed attributes are tightly integrated. We suggest that understanding the roles of fruit chemistry in any vertebrate-dispersed fruit will require consideration of selection pressures occurring before, during, and after dispersal, and consideration of trade-offs occurring within and between fruit and seed phenotypes (Cipollini and Levey 1997, Cipollini 2000, Levey et al. 2007). Yet the roles of these chemicals as mediators of gut retention are particularly striking: all fruit secondary compounds tested thus far in natural dispersers have been shown to affect gut retention time of seeds (Murray et al. 1994, Wahaj et al. 1998, Tsahar et al 2003). Capsaicin is no exception; it has consistent effects on gut retention across distantly related birds on two continents, but the outcomes of this interaction depend critically on seed morphology and consumer physiology.

In summary, chilies are not "hot" for any particular reason, but for multiple reasons that vary across species and life history stages. A clear implication is that studies on the function of secondary compounds need to be framed broadly and need to recognize that production of secondary metabolites does not occur in an ecological vacuum: capsaicin and other "secondary" metabolites probably compete with primary (physiological) functions. Such trade-offs between secondary and primary functions not only reveal potential costs of secondary metabolite production, but also imply that selection on fruit chemistry, whether by vertebrates or microbes, can modify seemingly unrelated fruit traits.

\section{ACKNOWLEDGMENTS}

For assistance in the field, we thank Noelle Beckman, Rob Dobbs, Ian Horn, and Anna Maria "Pocho" Saavedra. Fundación Amigos de la Naturaleza, Wildlife Conservation
Society-Bolivia, Museo de Historia Natural "Noel Kempf Mercado," Don Alfonso of Rancho San Julian, Suzanne Nelson of Native Seeds SEARCH, and Courtney Conway provided logistical support for which we are grateful. Two anonymous reviewers provided many useful comments on a previous draft of the manuscript. This research was supported by grants from the National Science Foundation (DEB 0129168) and the National Geographic Society (CRE 7190-02)

\section{Literature Cited}

Alcántara, J. M., and P. J. Rey. 2003. Conflicting selection pressures on seed size: evolutionary ecology of fruit size in a bird-dispersed tree, Olea europaea. Journal of Evolutionary Biology 16:1168-1176.

Alvarez, P. J. C., F. C. Krzyzanowski, J. M. G. Mandarino, and J. B. F. Neto. 1997. Relationship between soybean seed coat lignin content and resistance to mechanical damage. Seed Science and Technology 25:209-214.

Atanassova, B., L. Shtereva, Y. Georgieva, and E. Balatcheva 2004. Study on seed coat morphology and histochemistry in three anthocyaninless mutants in tomato (Lycopersicon esculentum Mill.) in relation to their enhanced germination. Seed Science and Technology 32:79-90.

Baraloto, C., P. M. Forget, and D. E. Goldberg. 2005. Seed mass, seedling size and neotropical tree seedling establishment. Journal of Ecology 93:1156-1166.

Barnea, A., Y. Yom-tov, and J. Friedman. 1991. Does ingestion by birds affect seed germination? Functional Ecology 5:394402

Baskin, C. C., and J. J. Baskin. 2001. Seeds: ecology, biogeography, and evolution of dormancy and germination. Academic Press, San Diego, California, USA.

Bronstein, J. L., I. Izhaki, R. Nathan, J. J. Tewksbury, O Spiegel, A. Lotan, and O. Altstein. 2007. Fleshy-fruited plants and frugivores in desert ecosystems. Pages 148-177 in A. J. Dennis, E. W. Schupp, R. J. Green, and D. A. Westcott, editors. Seed dispersal: theory and its application in a changing world. CAB International, Wallingford, UK

Cipollini, M. L. 2000. Secondary metabolites of vertebratedispersed fruits: evidence for adaptive functions. Revista Chilena De Historia Natural 73:421-440.

Cipollini, M. L., and D. J. Levey. 1997. Secondary metabolites of fleshy vertebrate-dispersed fruits: adaptive hypotheses and implications for seed dispersal. American Naturalist 150:346372.

Clark, J. S., M. Lewis, J. S. McLachlan, and J. Hille Ris Lambers. 2003. Estimating population spread: what can we forecast and how well? Ecology 84:1979-1988.

Cottrell, H. J. 1947. Tetrazolium salt as a seed germination indicator. Nature 159:748

Crawley, M. J. 2002. Statistical computing: an introduction to data analysis using S-Plus. John Wiley, West Sussex, UK.

Denslow, J. S., D. J. Levey, T. C. Moermond, and B. C. Wentworth. 1987. A synthetic diet for fruit-eating birds. Wilson Bulletin 99:131-135.

Dixon, R., and N. Paiva. 1995. Stress-induced phenylpropanoid metabolism. Plant Cell 7:1085-1097.

Herrera, C. M. 1982. Defense of ripe fruit from pests: its significance in relation to plant-disperser interactions. American Naturalist 120:218-241.

Herrera, C. M. 1986. Vertebrate dispersed plants: why they don't behave the way they should? Pages 5-18 in A. Estrada and T. H. Fleming, editors. Frugivores and seed dispersal. Dr. W. Junk, Dordrecht, The Netherlands.

Herrera, C. M. 1998. Long-term dynamics of Mediterranean frugivorous birds and fleshy fruits: a 12-year study. Ecological Monographs 68:511-538.

Hosmer, D. W., and S. Lemeshow. 2000. Applied logistic regression. Second edition. Wiley Interscience, New York, New York, USA 
Hulme, P. E., and C. W. Benkman. 2002. Granivory. Pages 132-156 in C. Herrera and O. Pellmyr, editors. Plant-anima interactions, an evolutionary approach. Blackwell, Oxford, UK

Izhaki, I., and U. N. Safriel. 1990. The effect of some Mediterranean scrubland frugivores upon germination patterns. Journal of Ecology 78:56-65.

Janzen, D. H. 1981. Enterolobium cyclocarpum seed passage rate and survival in horses. Costa Rican Pleistocene seed dispersal agents. Ecology 62:593-601.

Janzen, D. H. 1984. Dispersal of small seeds by big herbivores: foliage is the fruit. American Naturalist 123:338--353.

Johnson, R. A., M. F. Willson, J. N. Thompson, and R. I. Bertin. 1985. Nutritional values of wild fruits and consumption by migrant frugivorous birds. Ecology 66:819-827.

Jordano, P. 1992. Fruits and frugivory. Pages 105-151 in M. Fenner, editor. Seeds: the ecology of regeneration in natural plant communities. CAB International, London, UK

Levey, D. J., and A. Grajal. 1991. Evolutionary implications of fruit-processing limitations in Cedar Waxwings. American Naturalist 138:171-189.

Levey, D. J., and W. H. Karasov. 1992. Digestive modulation in a seasonal frugivore, the American Robin (Turdus migratorius). American Journal of Physiology 262:G711G718

Levey, D. J., A. R. Place, P. J. Rey, and C. Martinez del Rio. 1999. An experimental test of dietary enzyme modulation in pine warblers Dendroica pinus. Physiological and Biochemica Zoology 72:576-587.

Levey, D. J., J. J. Tewksbury, M. L. Cipollini, and T. A. Carlo. 2006. A field test of the directed deterrence hypothesis in two species of wild chili. Oecologia 150:51-68.

Levey, D. J., J. J. Tewksbury, I. Izhaki, E. Tsahar, and D. C. Haak. 2007. Evolutionary ecology of secondary compound in ripe fruit: case studies with capsaicin and emodin. Pages 37-58 in A. J. Dennis, E. W. Schupp, R. J. Green, and D. A. Westcott, editors. Seed dispersal: theory and its application in a changing world. CAB International, Wallingford, UK.

McLeod, M. J., S. I. Guttman, and W. H. Eshbaugh. 1982 Early evolution of chile peppers (Capsicum). Economic Botany 36:361-386

Murray, K. G., S. Russell, C. M. Picone, K. Winnett-Murray, W. Sherwood, and M. L. Kuhlmann. 1994. Fruit laxatives and seed passage rates in frugivores: consequences for plan reproductive success. Ecology 75:989-994.

Nathan, R., and H. C. Muller-Landau. 2000. Spatial patterns of seed dispersal, their determinants and consequences for recruitment. Trends in Ecology and Evolution 15:278-285.

Norusis, M. J. 2003. SPSS 12.0 statistical procedures companion. Prentice Hall, Englewood Cliffs, New Jersey, USA

Perramond, E. 2005. The politics of ecology: local knowledge and wild chili collection in Sonora, Mexico. Journal of Latin American Geography 4:59-75.

Rasband, W. S. 1997-2006. Image J, U. S. National Institutes of Health, Bethesda, Maryland, USA. 〈http://rsb.info.nih. gov/ij/
Rice, W. R. 1989. Analyzing tables of statistical tests. Evolution 43:223-225.

Schupp, E. W. 1995. Seed-seedling conflicts, habitat choice, and patterns of plant recruitment. American Journal of Botany 82:399-409.

Stanley, M. C., and A. Lill. 2002. Does seed packaging influence fruit consumption and seed passage in an avian frugivore? Condor 104:136-145.

Sukrasno, N., and M. M. Yeoman. 1993. Phenylpropanoid metabolism during growth and development of Capsicum fructescens fruits. Phytochemistry 32:839-844.

Tewksbury, J. J., C. Manchego, D. C. Haak, and D. J. Levey. 2006. Where did the chili get its spice? Biogeography of capsaicinoid production in ancestral wild chili species Journal of Chemical Ecology 32:547-564.

Tewksbury, J. J., and G. P. Nabhan. 2001. Directed deterrence by capsaicin in chillies. Nature 412:403-404

Tewksbury, J. J., G. P. Nabhan, D. Norman, H. Suzan, J. Tuxill, and J. Donovan. 1999. In situ conservation of wild chiles and their biotic associates. Conservation Biology 13 98-107.

Traveset, A. 1998. Effect of seed passage through vertebrate frugivores' guts on germination: a review. Perspectives in Plant Ecology, Evolution and Systematics 1:151-190.

Traveset, A., A. Roberstson, and J. Rodríguez-Pérez. 2007. A review on the role of endozoochory on seed germination. Pages 78-103 in A. Dennis, R. Green, E. Schupp, and D. Westcott, editors. Seed dispersal: theory and its application in a changing world. CABI Publishing, Wallingford, UK

Traveset, A., J. Rodríguez-Pérez, and B. Pías. 2008. Seed trait changes in dispersers' guts and consequences for germination and seedling growth. Ecology 89:95-106.

Traveset, A., and M. Verdú. 2001. A meta-analysis of the effect of gut treatment on seed germination. Pages 339-350 in D. J. Levey, W. R. Silva, and M. Galetti, editors. Seed dispersal and frugivory: ecology, evolution, and conservation. CABI Publishing, Wallingford, UK.

Tsahar, E., J. Friedman, and I. Izhaki. 2003. Secondary metabolite emodin increases food assimilation efficiency of Yellow-vented Bulbuls (Pycnonotus xanthopygos). Auk 120: 411-417.

Verdú, M., and A. Traveset. 2005. Early emergence enhances plant fitness: a phylogenetically controlled meta-analysis Ecology 86:1385-1394.

Wahaj, S. A., D. J. Levey, A. K. Sanders, and M. L. Cipollini. 1998. Control of gut retention time by secondary metabolites in ripe Solanum fruits. Ecology 79:2309-2319.

Walsh, B. M., and S. B. Hoot. 2001. Phylogenetic relationships of Capsicum (Solanaceae) using DNA sequences from two noncoding regions: the chloroplast atpB-rbcL spacer region and nuclear waxy introns. International Journal of Plant Science 162:1409-1418.

Willson, M. F., and C. J. Whelan. 1990. The evolution of fruit color in fleshy-fruited plants. American Naturalist 136:790 809 